\title{
Empirical Evidence on the J-Curve Between Pakistan and Selected South Asian Trade Partners
}

\author{
Waqar Khalid \\ School of Economics, Quaid-I-Azam University, Islamabad, Pakistan
}

Email address:

waqarkhalidicp@yahoo.com

\section{To cite this article:}

Waqar Khalid. Empirical Evidence on the J-Curve Between Pakistan and Selected South Asian Trade Partners. European Business \& Management. Vol. 3, No. 4, 2017, pp. 57-64. doi: 10.11648/j.ebm.20170304.11

Received: July 4, 2017; Accepted: July 12, 2017; Published: August 3, 2017

\begin{abstract}
The earlier researches investigated the J-curve hypothesis along with the Marshall-Lerner condition in Pakistan used the OLS, 2SLS, 3SLS, and Instrumental Variables (IV) techniques. The estimates obtained from these studies may suffer from spurious regression problems as the models were estimated without incorporating the co-integrating property of the variables. Hence, the objective of this work is to analyze the trade balance model using relatively the new co-integration approach, the ARDL model. The J-curve phenomenon is tested for Pakistan's trade with her selected South Asian trade partners, including Republic of India and Democratic Socialist Republic of Sri Lanka using the annual time series data over the 1975-2013 periods. After empirical analysis, it was observed that the J-curve occurrence is rejected in favor of Pakistan with its trading partners. This study concludes that depreciation of Pakistani Rupee has a constructive result on Pakistan's trade with these trade partners.
\end{abstract}

Keywords: J-curve, Depreciation, Trade Balance, Cointegration, Pakistan, India, Sri Lanka

\section{Introduction}

Devaluation or depreciation of currency is a policy that economies adopt in certain conditions to get better its trade's performance. The impact of the depreciation of currency is different in the short plus in the long period on the balance of trade for the concerned economy. At the beginning, this policy has a downbeat effect lying on the balance of trade; however, with the passageway of time improvement occurs. This movement of the trade balance to worsen initially and then its improvement is described by the economist with the $\mathrm{J}$-curve. This phenomenon describes a "J" formed time series diagram in which the curve initially falls up to certain level and then slowly rises to an upper level. This effect is not only found in a trade balance of an economy but also in the equity funds returns, i-e. In the beginning, the equity funds yield downbeat per annum returns resulting from initial costs and high administration and managerial fees. Though, once a fund matures, its value steadily rises showing positive trend and beyond its opening value.

Trade balance is one of the basic objectives of policy making in the field of International Economics. From the partition since 1947, Pakistan faces the trade deficit due to many reasons, like narrow trade base, consumption oriented society, less modernization of machinery, less production of value added goods, technical barriers, increase in prices of inputs, devaluation of currency, foreign debt servicing, import of capital goods, the rise in oil prices, increases in import payment of fertilizer, political uncertainty, etc. In order to perk up the trade balance, the policy experts may focus on export promotion policies or import restriction policies which depend upon the health of an economy. In case of Pakistan, devaluation of currency is the main focused on the government, which helps to make home goods cheaper as compare to the international market goods which direct to enlarge in demand by foreigners for Pakistan's merchandise and yields more foreign exchange reserve with the country in a result.

While on the other hand, this policy has an unfavorable impact on the economy's trade as well, i-e. This policy discourages imports as import prices have risen up than before. Hence, devaluation of currency has a dual effect. With this policy, initially, the country's total amount of imported goods may exceed its total amount of exports, resulting in a trade shortfall in that nation. But finally, the currency depreciation reduces the price of its exported commodities. As a result, the country exports level slowly 
but surely maintained, plus the state goes reverse to an excess position, leading towards favorable balance of payments. The devaluation of currency can affect the balance of trade positively only if the summation of export \& import elasticity is larger than unity and the condition is known as MarshallLerner condition and is a pre-requisite to improve balance of trade through the devaluation of currency.

Since the partition, Pakistan has a history of trade deficit and unfavorable balance of payments. On several occasions, Pakistan's currency is devalued, which have effects on the several macro-economic variables, for instance, inflation rate, exchange rate, exports, imports, terms of trade, increasing revenue collection, inflow of foreign capital, etc. Devaluation of currency is generally experienced as a way of minimizing a debit in the balance of payment.

Many experts having views so as to deteriorating the currency value might is in fact be fine in favor of the country, because a weaker exchange must heighten the manufacturing production, consecutively resolve and pinch jobs, also this set will results growth. Conversely, by falling currency value (rupee) excessively speedily, would be that the foreigners will stop foreign direct investment (FDI) in the country, due to which financing of the current account deficit becomes difficult and even impossible. As a result, the interest rate policy has changed i-e. The rate of interest will be forced to push up to depend Pakistan's currency, and finally, this step could create a recession in the economy which is an alarming and more severe situation.

After the partition, Pakistan had first experienced devaluation of its currency during the Post-Korean War recession in the year 1955. The subsequent major change in the exchange rate was the devaluation on $11^{\text {th }}$ May 1972 during the Pakistan's Peoples Party Parliamentarians (PPPP) government. The Pakistani rupee was devalued by $56.7 \%$. The basic objective behind this policy was the expected increase in Pakistan's exports, but the capital account deficit could not be reduced. The recent depreciation of Pakistani rupee against U.S. dollar since 2006 has also been unable to improve the balance of payment situation due to many reasons.

This empirical study, therefore, is an attempt to investigate whether devaluation/ depreciation has any relationship with trade balance over the time in case of Pakistan. The International economics theory predicts a J-curve type relationship which means that due to the devaluation of currency, initially the trade balance deteriorates and with respect to time the improvement occurs in the trade balance.

The remaining article will proceed as follows. Section 2 deals with the literature review. In section 3, the variables description, data sources and the methodology is given. Section 4 shows the results and section 5 is conclusion of the study.

\section{Literature Review}

Over the last half century, a bulky number of works conducted by the researchers that examines the J-curve hypothesis. Due to devaluation of currency, the J-curve shows the downbeat effect on trade balance in the small period while the encouraging result on trade balance in the time-consuming period. The difference is because of the short and long period difference in demand elasticity of imports and exports.

The same hypothesis have been tested by many scholars, such as [18], [16], [17], [12], [7] and found conflicting results. Among these studies, some of the scholars were used the aggregate data while the other ones analyzed the J-curve literature using the disaggregate data. Similarly, few studies tested only the J-curve hypothesis, whereas the remaining studies focus on the Marshall-Lerner condition as well.

[23] was the very earliest attempt in the science of International Economics to sketch out prospect of the Jcurve. For the being of a worsening balance of trade in the wake of currency, he put forward two possible reasons. The first reason was the contract rigidities that take time to diminish. The next reason was that there is a lead through effect of currency depreciation on domestic prices, which may not take place until some time has passed after such depression. Hence, in consequence, the constructive possessions of exchange rate reduction possibly will not be instantly noticeable still though the long period elasticity's satisfy the ML condition.

[21] employed the ARDL model so as to check the J-curve evidence in the Laos economy. After analyzing the model, they conclude that the Laos economy supports the hypothesis of the J-curve. This study reports the inverse result of currency devaluation on the TB in the short term. In case of long term, this study suggests that the J-curve effect becomes positive though it is insignificant.

[18] used the quarterly data from the year 1973-1980 for four developing countries, including India, Thailand, Greece and Korea. He investigates the connection between the devaluation of the currency and trade balance. The author also examines the J-curve effect by applying the Almon lag technique. The empirical results suggest the J-curve pattern for the countries except Thailand. He also found that the long period and the short period effect of depreciation of currency is the same.

[16] reviewed the testing of the J-curve hypothesis and its hypothetical groundwork. These authors have classified the empirical articles into two main classes. The classification of classes was based on the aggregation of trade data. In the first class, they included the cases that have experienced the Jcurve phenomenon between one country and the others based on the aggregation of data, and due to using collective data, they experience the aggregation bias. On the way to eliminate the problem, the second class accounts the studies that use individual type trade data to check the same phenomenon between different economies.

[8] used the periodical data covering the 1974Q1-2008Q4 periods. They disaggregate the Indonesian trade data with her 13 key trading allies, which contribute over $50 \%$ trade with Indonesia and by utilizing the ECM, they examined the Jcurve hypothesis for Indonesia and its 13 trade associates. 
For UK, Canada, Japan, Malaysia and Singapore out of 13 trading countries, they established the verification of the Jcurve hypothesis and institute a noteworthy long run coefficient for exchange rate.

[29] have investigated the connection involving the exchange rates and balance of trade intended for the seven East Asian economies in the short period as well as in the long period, using the quarterly data from 1980Q1-1998Q4. They $1^{\text {st }}$ examine stationary condition for each variable in the data set for all the countries. By applying the co-integration test, they found a long term association between balance of trade and the exchange rate. They also found that in modeling the East Asian trade balances the short run dynamics based on the ECM can play a significant role. And lastly, they found that there exists a J-curve phenomenon for all the East Asian countries except Japan by applying the impulse response function.

Another study by [19] used the Johansen \& Juselius ML co-integration methodology (1990) to calculate the MarshallLerner condition used for the 06 nations by applying the data covering the 1973Q1-1990Q4 periods. The findings show that the Marshall-Lerner condition was not satisfied for Pakistan because this finding was based on the aggregate trade data. These results were contradictory with [1] who have applied the Johansen and Juselius methodology, using the quarterly data from the year 1980 to 2000 . The findings prove that the Marshall-Lerner condition in the long run for Pakistan is fulfilled now. In fact, the method they used is a development over the [19] but it may perhaps still experience from aggregation bias because for each entity trading partner the bilateral trade data were not applied. [25] have found no cause of the devaluation of dollar on the trade balance involving USA \& her six trading followers in the short as well as in the long period. This study confirms the existence of Marshall-Lerner condition for USA with Japan, UK, France and Italy, while for USA trade with Canada and Germany there was no evidence of subsistence of the Marshall-Lerner condition [10].

[4] considered the exchange rate depreciation and its impact on the trade balance, both the short term and the long term, in a dynamic modeling. The author investigated the continuation of the J-curve in Turkey by data from 1987Q1 to 2000Q4. For the differentiation of short plus long run equilibrium dynamics, the author used the ECM technique. After that he considered the Generalized Impulse Response methodology so as to examine the react of the balance of trade to the exchange rate depreciation. The outcome does not support the J-curve happening in the short period. While, in the long period the Marshall-Lerner condition satisfied for the Turkey data which shows that the depreciation improves the balance of trade.

As this study deals with the case of Pakistan on the J-curve literature, therefore it is necessary to provide a brief summary of the works related to Pakistan so that the outcome of this analysis can be effectively distinguished. [3] have estimated the reduced trade balance model using ARDL technique to launch the practical evidence of the J-curve experience. The authors used the quarterly data over 1972-2002 with the aim of check the J-curve phenomenon in Pakistan. They used the [10] log form linear model for estimation. For the identification and estimation of J-curve, they used the tools of co-integration and the Error Correction. They explore the long run shock of depreciation of Pakistan's Rupee on its balance of trade using the aggregate data. The confirmation of a J-curve phenomenon is originated, but the long period impact of real depreciation of Pakistan's currency was not approving. According to the author's findings, the basic reason behind this limitation was the use of aggregate trade data.

[7] by quarterly data from 1980-2006 analyzed the correlation between the exchange rate and balance of trade for Pakistan's economy. After analyzing the statistics, they noticed negative elasticity which reveals the downbeat consequence of currency fall on the trade balance. To cointegration test, they separated the whole data set into two sub-groups, i-e the $1^{\text {st }}$ sample from 1980-1990, the fixed exchange era and the $2^{\text {nd }}$ sample from 1991-2006, the floating exchange era. For long run relationships and elasticity's they have applied the ARDL methodology, and they found the long term relationship between balance of trade and the exchange rate. They also found that for the sample and for sub sample the noteworthy and depressing elasticity's shows that the devaluation will direct to deteriorating the balance of trade. They furthermore found that the J-curve does not exist for Pakistan.

[9] examined the exchange rate volatility on the balance of trade between Pakistan and her thirteen trade partners in the short as well as in the long run. This study is different from other studies in the logic that it applies both the aggregate trade data and disaggregates level data to check out the Jcurve effect for each type. After the analysis, it was found no significant effects of currency depreciation on the trade balance between the Pakistan and its trade partners. Conversely, using bilateral trade flows, there was confirmation of noteworthy short and long run effects of currency depreciation on the trade balance between Pakistan and her trade partners no less than in six cases, whereas there was no substantial effect found between Pakistan and the US in both periods. Similarly, other studies have been conducted by many researchers including [2], [26], [27] and [28], etc. and have tested the impact of currency depreciation on the trade balance between Pakistan and her trade partners. In the conclusion, all of them were found the failure of the J-curve phenomenon, suggested the favorable effects of currency depreciation on the trade balance for Pakistan.

Lastly, the most recent study given by [13] analyzed the Jcurve phenomenon using aggregate data between Pakistan and the U.S. and finds no significant effects of currency devaluation on the trade balance. When they used the disaggregated trade flows by commodity between the two trade partners, they find significant short run effects (the JCurve) for seventeen industries out of the forty five industries. Correspondingly, the largest industry looks to benefit from real depreciation of currency in the long run. 


\section{The Methodology}

To check out the effects of changes in the exchange rate of a currency on the bilateral trade balance in the short and in the long run, we estimate and regress the trade balance equation straight on the exchange rate, though keeping the effects of real income in domestic country as well as in foreign countries. For this purpose, I have used the time series data covering the $1975-2013$ periods. Data on the bilateral exports and imports were taken from the World Integrated Trade Solution (WITS), while the exchange rate data has been taken from the International Financial Statistic (IFS). Similarly, data on the real GDP $\left(G D P_{R}\right)$ have been taken from the World Development Indicators (WDI).

The proposed trade balance model for Pakistan and its trade competitors $i(i=1,2)$, I used the same model as were used by different researchers in different times, including [10] and [6], is given in the Equation (1):

$$
\log T B_{i, t}=\alpha+\beta \log Y_{\text {Pakistan }, t}+\gamma \log Y_{i, t}+\emptyset \log R E X_{i, t}+\epsilon_{t}
$$

This is the equation in logarithmic form which shows the trade balance between Pakistan and its selected trading allies $i$, where $\left(T B_{i}\right)$ is the trade balance. Here, $\left(T B_{i}\right)$ is the dependent variable which depends on or a function of Pakistan's real GDP ( $\left.Y_{\text {Pakistan }}\right)$, GDP of trade associate $i\left(Y_{i}\right)$, the real bilateral exchange rate $\left(R E X_{i}\right)$ and $\epsilon_{t}$ is the stochastic disturbance term. Besides, the subscript " $t$ " shows the time unit in years.

The International trade theory suggests that when the county GDP increases over the periods; its imports will automatically rises, therefore; we guess the value of $\beta$ to be positive after analysis. Alternatively, if home country's GDP increases and which reflect improvement in the production of imports substitution products, then the negative estimate of $\beta$ is possible in that case. Similarly, as the GDP/income increases of foreign country (trading partner), Pakistan's exports will boost up, therefore, we guess coefficient of $\gamma$ to be negative. Alternatively, if GDP increases in foreign country leads to an improvement in foreign production of substitutes for Pakistani export goods, we guess value of $\gamma$ to be encouraging. Lastly, decrease in the value of $R E X_{i}$ reflects a depreciation of Pakistan's currency. The coefficient of $R E X_{i}$ which is $\varnothing$ would be positive, if trade balance improves, i-e. Depreciation of currency decreases imports from foreign and increases exports of domestic goods to foreign.

It is noticed that the specification given in equation (1) will capture the long run relation between the trade balance and exchange rate depreciation only while the J-curve phenomenon occurs in the short term; therefore, we need some modifications. In order to confine the short term dynamics of currency depreciation on balance of trade, the modified form, error correction modeling, following [24] and is given in Equation (2):

$$
\begin{gathered}
\Delta \log T B_{i, t}=\alpha+\sum_{k=1}^{n} \eta k \Delta \log T B_{i, t-k}+\sum_{k=0}^{n} \beta_{k} \Delta \log Y_{c, t-k}+\sum_{k=0}^{n} \gamma k \Delta \log Y_{i, t k}+\sum_{k=0}^{n} \emptyset_{k} \Delta \log R E X_{i, t-k}+\delta_{1} \log T B_{i, t-1}+ \\
\delta_{2} \log Y_{\text {Pakistan }, t-1}+\delta_{3} \log Y_{i, t-1}+\delta_{4} \log R E X_{i, t-1}+u_{t}
\end{gathered}
$$

Since this study intended to include 02 major trading partners of Pakistan for our empirical analysis. Due to nonavailability of the time series data as well as some estimation problems, we therefore had to discard the remaining South Asian countries for our empirical analysis. This study therefore includes two South Asian countries, India and Sri Lanka for our empirical analysis. All the variables included for this study were stationary at the first lagged and are $I(1)$. For justification of lagged level variables, we must check either their coefficients are mutually considerable (significant) or not. i-e., $H_{0}: \delta_{1}=\delta_{2}=\delta_{3}=\delta_{4}=0$ is tested in opposition to the $H_{1}$ : At least one of them may not equal to zero, where $H_{0}$ indicates that there is no co-integration relationship exist and the variable are not co-integrated with each other.

[24] suggested by using the F-statistic and its tabulated critical values. A higher critical value and a lower critical value are tabulated if all variables are $I(1)$ and $I(0)$, respectively. If $H_{0}$ is accepted, it means there is no cointegrating relationship exists and vice versa. In this manner, the short termsound impact of depreciation of currency is captured by the coefficients of $\emptyset_{k}{ }^{\prime}$ s. Note that if the lower lags negative values followed by positive estimated values for upper lags will reveal the existence of a J-curve phenomenon, otherwise not.

\section{Empirical Results}

The variables that having the long run relationship among themselves having the same or different order of integration which we called a co-integrating relationship, and the estimation technique are known as the co-integration analysis. The various co-integration techniques used in the literature consists of the Engle-Granger Methodology, Auto Regressive Distributed Lag (ARDL) model or Johansen technique which can be applied for analysis based on the nature (order) of integration of the given variables used for estimation and analysis. The possibility of time dependence in time series data can result in the spurious regression which does not show us the real association among the variables in the model, therefore, the foremost step in the co-integration investigation would be to check the variables for stationary.

The variables we have taken for the analysis were stationary in the first lag differences by applying the UR test. The different tests have been used in the literature for a unit root checking, like the PP test, the DF test, the ADF test, etc. The most common used among these all tests is the Augmented-Dickey Fuller (ADF) test due to its property of relaxing the assumption of serial correlation among the errors. If a variable comes out to be level stationary it is 
denoted as $I(0)$ and is called as integrated of order zero. On the other hand, if a variable is stationary at the first difference, it is denoted as $I(1)$ and said to be integrated of order one. To catch the long period relation among the variables and an appropriate estimation technique, the order of integration is very important. The outcome of the ADF test for each variable is given in the table 1.

Table 1. ADF Test Results.

\begin{tabular}{lllll}
\hline Variable & Level & Lags & First difference & Lags \\
\hline Pakistan & & & & \\
REX & 1.869 & 1 & -3.389 & 1 \\
LnY & -2.141 & 2 & -3.887 & 0 \\
LnM & -1.603 & 1 & -5.367 & 1 \\
LnX & -1.225 & 1 & -4.678 & 1 \\
India & & & & \\
REX & 0.290 & 1 & -3.128 & 1 \\
LnY & 2.151 & 1 & -4.083 & 1 \\
LnM & -0.455 & 1 & -6.691 & 1 \\
LnX & -0.595 & 1 & -4.037 & 0 \\
Sri Lanka & & & & \\
REX & 1.149 & 1 & -4.140 & 1 \\
LnY & 1.206 & 1 & -3.156 & 1 \\
LnM & -1.541 & 1 & -4.512 & 1 \\
LnX & -0.600 & 1 & -5.330 & \\
\hline
\end{tabular}

Note: All hypotheses are tested at $5 \%$ level of significance.

This table shows that all the given variables are $I(1)$. The second pace is the selection of proper lag length. These criteria includes Sequential modified LR test statistic, the FPE, the AIC, the SBC and the HQ. The most importantly used criteria are the AIC and the SBC. Our outcomes were fairly consistent across lag order choices.

In the identification and estimation of the J-curve, the cointegration and error correction approach have suggested being flourishing tools. Such type of technique to the J-curve captures the long run relationship between the TB and the REX, the short term behavior and its dynamics. The economic theory will specify us this long term equilibrium affiliation, whereas the short run behavior and dynamics can be known as from the underlying data generating process. To the examination of the J-curve phenomenon, there is an increasing literature on the application of co-integration and error correction models (ECM). The old application tended to be based on the Engle Granger co-integration methodology; however, more study suggested a new and comparatively better methodology advanced by [24] which is called the Auto-regressive distributive lag (ARDL) methodology. The ARDL approach has some important characteristics which are:

i. This technique can differentiate between dependent variable and independent variable in the estimation by avoiding the problem of endogeneity.

ii. This methodology can estimate the short period as well as the long period workings of the model all together by eliminating omitted variables troubles and autocorrelation. Hence, estimates obtained through this approach are efficient and unbiased.

iii. This approach can be functional irrespective of either the explanatory variables are $I(0)$ or $I(1)$.

In ARDL approach, the explanatory variables comprise past values of the explained variable plus the present $\&$ past values of one or more independent variables. The simplest example of an ARDL model is given below.

$$
Y_{t}=\alpha+\beta_{1} Y_{t-1}+\delta_{0} X_{t}+\delta_{1} X_{t-1}+\varepsilon_{t}
$$

This equation represents an $\operatorname{ARDL}(1,1)$, since the dependent variable $\left(Y_{t}\right)$ and single independent variable $\left(X_{t}\right)$ are each lagged once, and $\varepsilon_{t}$ is a white noise process. The estimated results and different diagnostic checks for India through the ARDL approach are given below in the table 2 .

Table 2. ARDL Results for India.

\begin{tabular}{lll}
\hline Variable & Coefficient & t-statistic \\
\hline C & -4.427 & $(-1.163)$ \\
D(LEXR) & -0.644 & $(-1.214)$ \\
D(LEXR(-1)) & -0.015 & $(-0.030)$ \\
D(LEXR(-2)) & -0.141 & $(-0.274)$ \\
D(LGDPI) & -3.450 & $(-1.609)$ \\
D(LGDPI(-1)) & -5.147 & $(-2.324)$ \\
D(LGDPI(-2)) & -3.726 & $(-1.388)$ \\
D(LGDPP) & 1.268 & $(0.700)$ \\
D(LGDPP(-1)) & -0.617 & $(-0.386)$ \\
D(LGDPP(-2)) & -0.354 & $(-0.236)$ \\
LEXR(-1) & 0.224 & $(0.837)$ \\
LGDPI(-1) & -0.418 & $(-1.291)$ \\
LGDPP(-1) & 0.796 & $(1.631)$ \\
LTB(-1) & -0.727 & $(-3.480)$ \\
$R^{2}$ & 0.541 & \\
Adj $R^{2}$ & 0.269 & --- \\
S.E. of regression & 0.053 & --- \\
SSR & 0.062 & --- \\
Log likelihood & 63.374 & --- \\
F-statistic & 1.991 & --- \\
Prob.(F-statistic) & 0.075 & --- \\
\hline
\end{tabular}

Similarly, the results and different diagnostics for Sri Lanka through the ARDL approach are given below in the table 3 .

Table 3. ARDL Results for Sri Lanka.

\begin{tabular}{lll}
\hline Variable & Coefficient & t-statistic \\
\hline C & 4.506 & $(0.562)$ \\
D(LEXRS) & -3.368 & $(-1.980)$ \\
D(LEXRS(-1)) & -0.506 & $(-0.654)$ \\
D(LEXRS(-2)) & 0.109 & $(0.148)$ \\
D(LEXRS(-3)) & 0.568 & $(0.723)$ \\
D(LGDPP) & -0.941 & $(-2.515)$ \\
D(LGDPP(-1)) & -0.504 & $(-0.953)$ \\
D(LGDPP(-2)) & -0.196 & $(-0.427)$ \\
D(LGDPP(-3)) & -0.335 & $(-0.849)$ \\
D(LGDPS) & -4.142 & $(-0.993)$ \\
D(LGDPS(-1)) & -3.310 & $(-0.873)$ \\
D(LGDPS(-2)) & -3.352 & $(-0.880)$ \\
D(LGDPS(-3)) & -5.152 & $(-1.367)$ \\
LEXRS(-1) & 0.154 & $(0.235)$ \\
LGDPP(-1) & 0.251 & $(0.413)$ \\
LGDPS(-1) & 0.357 & $(0.345)$ \\
LTB(-1) & -0.436 & $(-2.424)$ \\
$R^{2}$ & 0.537 & $(0.027)$ \\
Adj $R^{2}$ & 0.126 & --- \\
S.E. of regression & 0.133 & --- \\
\hline
\end{tabular}

There are several other statistics that could be useful for analysis of the J-curve phenomenon. Error correction model 
(ECM) is a theoretical determined technique helpful for estimating both the short \& the long run property of one time series on the other. The results obtained from the ECM are given below in the following tables.

Table 4. Short run Coefficient Estimates and Diagnostics.

\begin{tabular}{lll}
\hline INDIA & & \\
\hline Regressor & Coefficient Estimate & t-Ratio (Absolute value) \\
\hline D(LEXRS) & -0.73 & $(1.53)$ \\
D(LEXRS(-1)) & 0.18 & $(0.35)$ \\
D(LEXRS(-2)) & 0.16 & $(0.32)$ \\
D(LEXRS(-3)) & 0.05 & $(0.11)$ \\
ET(-1) & -0.53 & $(2.32)$ \\
R-squared & 0.25 & \\
Adjusted R-squared & 0.02 & \\
LM $\left(\chi^{2}\right)$ & 0.07 & \\
RESET $\left(\chi^{2}\right)$ & 0.07 & \\
SRI LANKA & & \\
D(LEXRS) & -1.74 & $(1.13)$ \\
D(LEXRS(-1)) & 0.29 & $(0.40)$ \\
D(LEXRS(-2)) & 0.65 & $(0.87)$ \\
D(LEXRS(-3)) & 0.14 & $(0.20)$ \\
ET(-1) & -0.34 & $(1.47)$ \\
R-squared & 0.20 & \\
Adjusted R-squared & 0.03 & \\
LM $\left(\chi^{2}\right)$ & 0.48 & \\
RESET $\left(\chi^{2}\right)$ & 0.54 & \\
\hline
\end{tabular}

Table 4 results show that here is refusal relationship exists between the REX and TB in the short run. Inspecting the short run dynamics in table 4 , it is gathered that the valid downgrading of Pakistani currency improves Pakistan on the whole TB in the short run, which came to known from the first three lagged coefficients of $\triangle L E X R S$ variable take positive coefficient. Hence, the short run coefficient of LEXRS is positive and insignificant, indicating there is no the J-curve type relationship exist.

Table 5. Estimated LR Coefficients of Bilateral TB Model.

\begin{tabular}{lll}
\hline INDIA & & \\
\hline Variable & Coefficient Estimate & t-Ratio (Absolute value) \\
\hline Constant $(\mathrm{C})$ & 0.75 & $(0.20)$ \\
Log GDP & -0.08 & $(0.22)$ \\
Log GDistan & 0.01 & $(0.04)$ \\
Log EXR & 0.00 & 0.02 \\
SRI LANKA & & \\
Constant $(\mathrm{C})$ & -0.81 & 0.16 \\
Log GDP & -0.40 & 1.31 \\
Log GDPistan & 0.28 & 0.48 \\
Log $E X R_{\text {SriLanka }}$ & -0.12 & 0.31 \\
\hline
\end{tabular}

Table 5 estimates explain that the co-efficient on the EXR for India is zero and in Sri Lanka it is negative, which is expected to be positive for each country in the long time period. The t-statistic value of the exchange rate is less than 1.65 for each trading partner which means that it is insignificant. Similarly, the coefficient on Pakistan's GDP $\left(G D P_{\text {Pakistan }}\right)$ is negative for each trading partner and is insignificant. These results do not present carry for a long run relationship between $G D P_{R}$ and her balance of trade. Hence, these outcome gestures that a long-run attachment between the EXR vs. TB do not exist.

The Langrangian Multiplier test of residual serial correlation having a chi-squared distribution with four $d . f$. Since it is noticed that the LM value is less than its critical value, it is accomplished that there is a lack of serial correlation. Similarly, Ramsey's RESET test for the functional specification, which is disseminated as chisquared with single d.f. This is a mis-specification test because we test $H_{0}$ against $H_{1}$ that does not indicate what the correct specification should be. As the RESET value is smaller than its critical value which indicates the reality that our model is correctly specified. This reveals the fact that variables are co-integrated.

Besides the above statistics, next [14], the solidity of short \& long run coefficient estimates is investigated by applying the CUSUM/CUSUMQSQ tests approved by [15]. For constancy of all the coefficients, the figure of the data necessity settles in 5\% significant values. The following figures revealed this fact in the case in India.

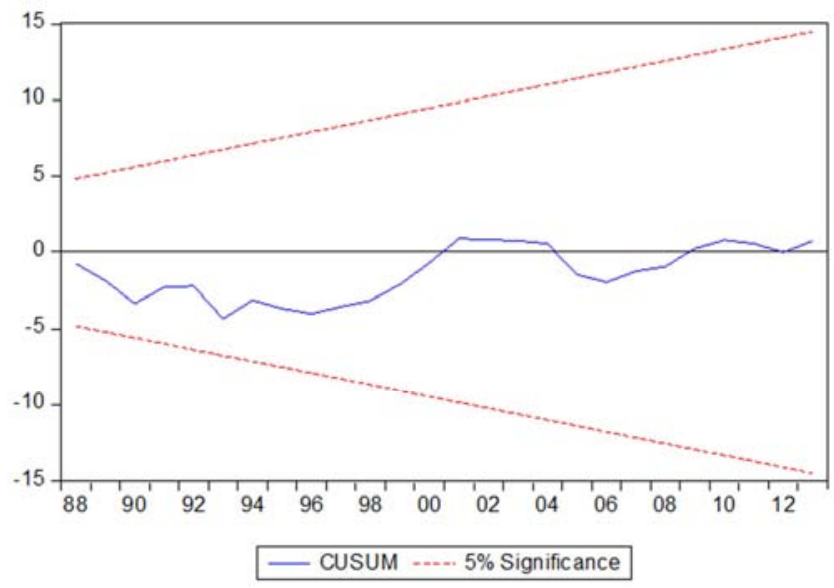

Figure 1. CUSUM Test Results for India.

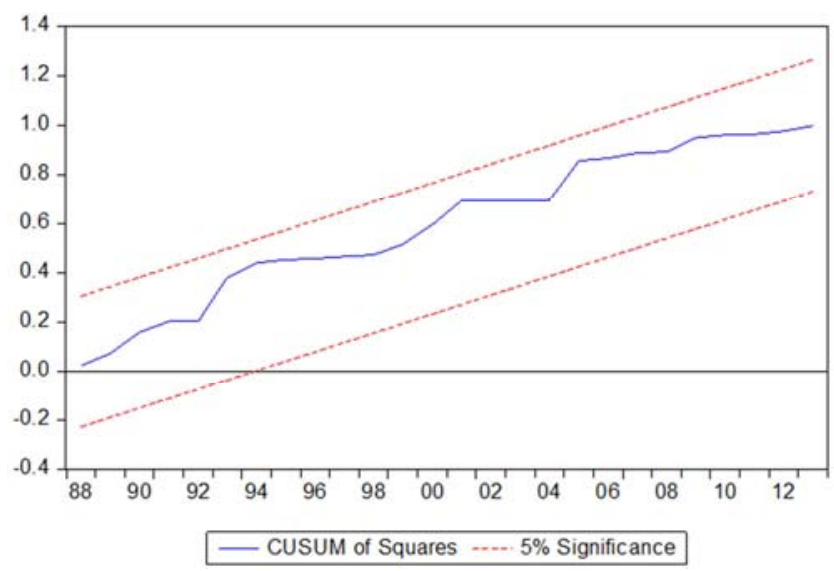

Figure 2. CUSUM of Squares Test Results for India.

Similarly, figure for Sri Lanka clearly reveals that the strength of estimates is confirmed since the design of CUSUMSQ falls inside the critical standards. 


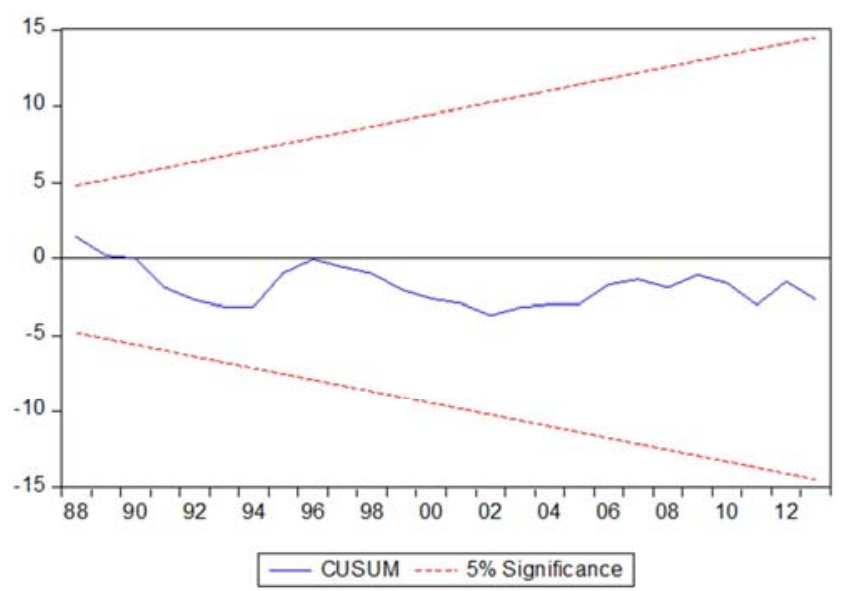

Figure 3. CUSUM Test Results for Sri Lanka.

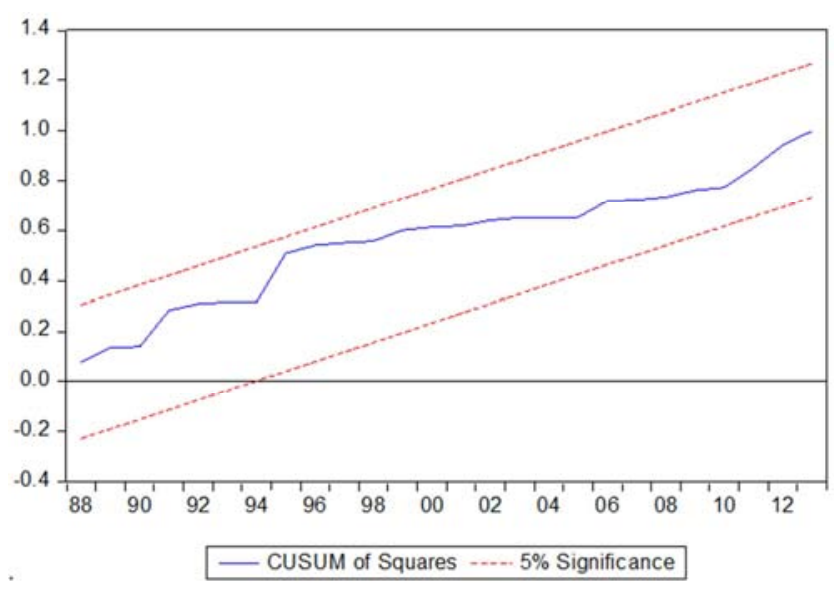

Figure 4. CUSUM of Squares Test Results for Sri Lanka.

\section{Conclusion}

Currency depreciation is the macroeconomic policy that is used by a country to advance trade activity. Though, this policy has different effects on the trade position of a country in the short plus the long period. In actual fact, an economy may well practice deterioration of her $T B$ in the short term prior to some enhancement that typically might appear in the long term. The major objective of this work is to estimate the $T B$ model so as to investigate the J-curve hypothesis empirically. For such purpose, the impact of depreciation of Pakistan's currency on Pakistan's trade balance in the long time period is empirically investigated by means of aggregate data sets. After investigating this phenomenon, it is found that depreciation of Pakistan's currency affects its trade balance positively in both periods, hence rejecting the verification of the J-curve.

\section{Future Research}

One major limitation of this article is that the investigator has used the aggregate set of data for the empirical investigation of the J-curve hypothesis for the Islamic Republic of Pakistan. The major trouble that might happen with this approach is the aggregation bias. Hence, it is left on the interested readers and researchers to inspect the Jcurve phenomenon between Pakistan and its main trading allies by using the recent developments in dynamic modeling.

\section{References}

[1] Aftab, Z. and Aurangzeb. (2002), "The Long Run and Short Run Impacts of Exchange Rate Devaluation on Pakistan's Trade Performance", The Pakistan Development Review, Vol. 41, No. 3, 277-86.

[2] Aftab, Z. and S, Khan. (2008), "Bilateral J-curve between Pakistan and Her Trading Partners", PIDE Working Paper No.2008:45.

[3] Afzal, M. and Rahman, H. (2004), "The J-Curve Phenomenon: An Evidence from Pakistan", Pakistan Economic and Social Review, Vol. 41, No. 1 (2), 45-58.

[4] Akbostanci, E. (2004), "Dynamics of the trade balance: The Turkish J-curve", Emerging Markets Finance and Trade, Vol. 40, No. 5, 57-73.

[5] A revisit.Inter disciplinary Journal of Contemporary Research in Business, 9 (3), 1456-67.

[6] Arora, S., Bahmani-Oskooee, M., and Goswami, G. G. (2003), "Bilateral J-curve between India and her trading partners", Applied Economics, Vol. 35, 1037-41.

[7] Awan, R., Shahbaz, M., Sher, F., and Javed, K. (2012),’Does J-Curve phenomenon exist in Pakistan".

[8] Bahmani-Oskooee, M. and Harvey, H. (2009), "The J-curve: Indonesia vs. Her Major Trading Partners", Journal of Economic Integration, Vol. 24, No. 4, 765-77.

[9] Bahmani-Oskooee, M. and Cheema, J. (2009), "Short run and long run effects of currency depreciation on the bilateral trade balance between Pakistan and her major trading partners." Journal of Economic Development, Vol. 34, No. 1.

[10] Bahmani-Oskooee, M. and T.J. Brooks (1999), "Bilateral JCurve between US and her Trading Partners", Weltwirtschaftliches Archive, Vol. 135, No. 1, 156-65.

[11] Bahmani-Oskooee, M., and J. Alse (1994), "Short-Run versus Long-Run Effects of Devaluation: Error-Correction Modeling and Co-integration", Eastern Economic Journal, Vol. 20, No. $4,453-464$.

[12] Bahmani-Oskooee, M. and J, Cheema. (2009), "Short-Run and Long-Run Effects of Currency Depreciation on the Bilateral Trade Balance between Pakistan and Her Major Trading Partners", Journal of Economic Development, Vol. 34, No. 1, 19-46.

[13] Bahmani-Oskooee, M., Iqbal, J., and Nosheen, M. (2015), "Commodity trade between Pakistan and the U. S: Is there evidence of the J-curve?"Applied Economics, 1-9.

[14] Bahmani-Oskooee, M. and Martian T. Bohl (2000), "German monetary unification and the stability of long-run German money demand function", Economics Letters, Vol. 66, 203-08.

[15] Brown, R. I., J. Durbin., and J. M. Evans (1975), "Techniques for testing the constancy of regression relations over time", Journal of Royal Statistical Society, Series- B37, 149-63. 
[16] Bahmani-Oskooee, M., and A. Ratha (2004a), "The J-Curve: A literature Review," Applied Economics, Vol. 36, No. 13, 1377-98.

[17] Bahmani-Oskooee, M. and Harvey, H. (2006), "How sensitive are Malaysia's bilateral trade flows to depreciation?Applied Economics, Vol. 38, No. 11, 1279-86.

[18] Bahmani-Oskooee, Mohsen. (1985), "Devaluation and the Jcurve: some evidence from LDCs", Review of Economics and Statistics, Vol. 67, 500-04.

[19] Bahmani-Oskooee, M. and Niroomand, F. (1998), "Long-run Price Elasticities and the Marshall-Lerner condition revisited", Economics Letters, Vol. 61, No. 1, 101-109.

[20] Krugman, P. R., Obstfeld, M., and Melitz, M. J. (2012), "International Economics, Theory \& Policy". Chapter-17, 447- 451 .

[21] Kyophilavong, P., Shahbaz, M., and Uddin, G. S. (2013), 'Does J-Curve phenomenon exist in case of Laos? An ARDL Approach", Journal of Economic Modeling, Vol. No. 35, 833839.

[22] Lowinger, T. A. (1978), "Domestic Inflation and Exchange Rate Changes: The Less-Developed Countries' Case," Weltwirtschaftliches Archive, Vol. 114, 85-100.
[23] Magee, S. P. (1973), "Currency contracts, pass through and devaluation", Brooking Papers on Economic Activity, Vol. 1, 303-25.

[24] Pesaran, M. H., Y. Shin., and R. J. Smith (2001), "Bounds Testing Approaches to the Analysis of Level Relationships", Journal of Applied Econometrics, Vol. 16, No. 03, 289-326.

[25] Rose, A. K. and Yellen, J. L. (1989), "Is there a J-curve?", Journal of Monetary Economics, Vol. 24, 53-68.

[26] Shahbaz, M. (2009), "On Nominal and Real Devaluations Relation: An Econometric Evidence for Pakistan", International Journal of Applied Econometrics and Quantitative Studies", Vol. 9, 86-108.

[27] Shahbaz, M., R, U. Awan, and K, Ahmad. (2011), "The Exchange Value of the Pakistan Rupee and Pakistan Trade Balance: An ARDL Bounds Testing Approach", The Journal of Developing Areas, Vol. 44, 69-93.

[28] Shahbaz, M., A, Jalil, and F, Islam. (2012). "Real Exchange Rate Changes and the Trade Balance: The Evidence from Pakistan", The International Trade Journal, Vol. 26, No. 2, 139-153.

[29] Lal, A. K. and Lowinger, T. C. (2002), “The J-curve: evidence from East Asia, "Journal of Economic Integration, Vol. 17, pp. 397-415. 